\title{
The microRNA-200 family acts as an oncogene in colorectal cancer by inhibiting the tumor suppressor RASSF2
}

\author{
JANE V. CARTER ${ }^{1,2^{*}}$, STEPHEN J. O'BRIEN $^{1 *}$, JAMES F. BURTON ${ }^{1}$, BRENT G. OXFORD ${ }^{1,3}$, \\ VINCE STEPHEN $^{1,3}$, JAKE HALLION ${ }^{1}$, CAMPBELL BISHOP ${ }^{1}$, NORMAN J. GALBRAITH ${ }^{1,4}$, \\ MAURICE R. EICHENBERGER ${ }^{1}$, HARSHINI SAROJINI ${ }^{1}$, EYAS HATTAB ${ }^{5}$ and SUSAN GALANDIUK ${ }^{1}$ \\ ${ }^{1}$ Price Institute of Surgical Research, University of Louisville School of Medicine, Louisville, KY 40202, USA; \\ ${ }^{2}$ Department of Surgery, North Cumbria University Hospitals NHS Trust, Carlisle, Cumbria CA2 7HY, UK; \\ ${ }^{3}$ School of Medicine, University of Louisville School of Medicine, Louisville, KY 40292, USA; \\ ${ }^{4}$ Department of Surgery, University Hospital Wishaw, Wishaw, North Lanarkshire ML2 0DP, UK; \\ ${ }^{5}$ Department of Pathology and Laboratory Medicine, University of Louisville School of Medicine, Louisville, KY 40202, USA
}

Received October 15, 2018; Accepted April 3, 2019

DOI: $10.3892 / 01.2019 .10753$

\begin{abstract}
This study aimed to determine whether manipulation of the microRNA-200 (miR-200) family could influence colon adenocarcinoma cell behavior. The miR-200 family has a significant role in tumor suppression and functions as an oncogene. In vitro studies on gain and loss of function with small interfering RNA demonstrated that the miR-200 family could regulate RASSF2 expression. Knockdown of the miR-200 family in the HT-29 colon cancer cell line increased KRAS expression but decreased signaling in the MAPK/ERK signaling pathway through reduced ERK phosphorylation. Increased expression of the miR-200 family in the CCD-841 colon epithelium cell line increased KRAS expression and led to increased signaling in the MAPK/ERK signaling pathway but increased ERK phosphorylation. Functionally, knockdown of the miR-200 family led to decreased cell proliferation in the HT-29 cells; therefore, increased miR-200 family expression could increase cell proliferation in the CCD-841 cell line. The present study included a large paired miR array dataset ( $n=632$ ), in which the miR-200 family was significantly found to be increased in colon cancer when compared with normal adjacent colon epithelium. In a miR-seq dataset $(n=199)$, the study found that miR-200 family expression was increased in localized colon cancer compared with metastatic disease. Decreased expression was associated with poorer overall
\end{abstract}

Correspondence to: Dr Susan Galandiuk, Price Institute of Surgical Research, University of Louisville School of Medicine, 511 S Floyd Street, Louisville, KY 40202, USA

E-mail:s0gala01@louisville.edu

*Contributed equally

Key words: microRNA-200 family, Ras association domain family member 2, MAPK pathway, colorectal cancer, oncogene survival. The miR-200 family directly targeted RASSF2 and was inversely correlated with RASSF2 expression $(n=199$, all $\mathrm{P}<0.001)$. Despite the well-defined role of the miR-200 family in tumor suppression, the present findings demonstrated a novel function of the miR-200 family in tumor proliferation.

\section{Introduction}

MicroRNAs (miRNAs) play a crucial role in the regulation of cell function through specific interactions with their messenger RNA (mRNA) counterparts. They are small, naturally occurring, non-protein coding RNA molecules that downregulate gene expression and affect subsequent protein expression $(1,2)$. miRNAs exhibit a variety of crucial regulatory functions related to cell growth, development, and differentiation $(3,4)$. When miRNAs are overexpressed in cancer, they may function as oncogenes or tumor suppressors, depending on their target mRNA $(5,6)$.

The miR-200 family consists of five members: miR-200a, miR-200b, miR-200c, miR-141, and miR-429. The miR-200 family is involved in cell transformation and tumorigenesis, cancer metastasis, tumor growth, angiogenesis, invasion, migration, and tumor cell survival in the circulation (intravasation and extravasation). miR-200 can be a potential diagnostic and prognostic tool in patients with cancer (7). Differential expression of the miR-200 family is involved in initiation and progression of malignant transformation. The miR-200 family regulates epithelial-to-mesenchymal transition (EMT), an important step in tumor progression $(8,9)$. The majority of cancer studies on the miR-200 family focus on its role in EMT regulation and tumor suppression. However, some authors report increased levels of the miR-200 family in various cancers, which contradicts the tumor suppressive role of this miRNA family (10).

This study focuses on colorectal cancer (CRC), which is the third-leading cause of cancer-related deaths in the United States. The underlying causes of CRC are complex and heterogeneous. Sporadic CRC is the most common presentation of 
CRC and develops from precursor polyps, namely advanced adenomas (11). KRAS mutations have been observed in $35-45 \%$ of colorectal adenocarcinomas (12-14). KRAS acts as a molecular on/off switch within the mitogen-activated protein kinase (MAPK) pathway, a major regulator of cell proliferation (15). This MAPK/ERK pathway is believed to be implicated in the pathogenesis, progression, and oncogenic behavior of CRC. Kinases within this pathway have the potential to be used as targets for the treatment of CRC (16).

It has been shown that the miR-200 family directly binds Ras association domain family member 2 (RASSF2), a negative regulator of $\operatorname{KRAS}(17,18)$; however, the relationship between miR-200 family, RASSF2, KRAS, and subsequent activity within the MAPK/ERK pathway in CRC, has not yet been fully described.

Our aim was to investigate the role of the miR-200 family in relation to MAPK/ERK signaling pathway activity and the effect upon cell proliferation mediated via the tumor suppressor RASSF2. We sought to determine whether manipulation of the miR-200 family could influence colon adenocarcinoma cell behavior and thereby have potential use as a therapeutic target.

\section{Materials and methods}

The present study was approved by the University of Louisville Institutional Review Board. For human studies, tissue samples were acquired from the University of Louisville Surgical Biorepository and written informed consent was obtained from all patients.

Cell line culture. Human colon cell lines, CCD-841 CoN (normal colon epithelium, cat. no. CRL-1790; ATCC ${ }^{\circledR}$, Manassas, VA, USA), HT-29 (colon cancer, cat. no. HTB-38; ATCC $^{\circledR}$ ), and T-84 (colon cancer, cat. no. CCL-248 ${ }^{\mathrm{TM}}$; ATCC ${ }^{\circledR}$ ) were prepared using the manufacturer's instructions. CCD-841 CoN cells were grown in Eagle's minimum essential medium. HT-29 cells were grown in McCoy's 5A. The T84 cell line were grown in Dulbecco's minimum essential medium supplemented with 15,10 , and $10 \%$ fetal bovine serum, respectively, with a $0.5 \%$ mixture of penicillin, streptomycin, amphotericin $\mathrm{B}$, and $0.5 \%$ L-glutamine. Cells were plated at 250,000 cells/well and allowed to grow to confluence before being harvested for RNA or protein extraction and stored at $-80^{\circ} \mathrm{C}$. Cell lines were tested regularly for mycoplasma and were authenticated using short tandem repeat analysis $\left(\mathrm{ATCC}^{\circledR}\right)$.

miRNA screening. The expression levels of 384 miRNAs were examined in the HT-29, T-84, and CCD-841 cell lines using TaqMan ${ }^{\circledR}$ low density array (TLDA) human miRNA card A following the manufacturer's protocol (Life Technologies, Carlsbad, CA, USA (19). RT-qPCR was performed using a ViiA $^{\mathrm{TM}} 7$ real-time PCR system (ThermoFisher Scientific, Inc., Middlesex, MA, USA). Expression levels of each individual miRNA were normalized to RNU6 (endogenous internal reference gene) using a cycle threshold of 0.1 to calculate $\Delta \mathrm{Cq}$ values for analysis using the comparative $\Delta \Delta \mathrm{Cq}$ method. The HT-29 cell line was chosen for further analysis as it was the most significantly dysregulated from the T-84 cell line. miRNA expression of the HT-29 cell line was compared to the miRNA expression of the CCD-841 CoN cell line.
miRNA single assay confirmation. Validation of significantly dysregulated miRNAs identified from screening was performed using specific TaqMan ${ }^{\circledR}$ miRNA primers and probes with RT-qPCR (Life Technologies, Carlsbad, CA, USA). Nucleic acid quantification was performed using a Step-One Plus RT-qPCR system (Life Technologies). The levels of each individual miR-200 family member (hsa-miR-429, cat. no: 4427975/assay ID: 001024, hsa-miR-200c, cat. no: 4427975/assay ID: 002300, hsa-miR-200b,cat.no: 4427975/assay ID: 002251,hsa-miR-200a cat. no: 4,427,975/assay ID: 000502, hsa-miR-141 cat. no: 4427975/assay ID: 000463) were normalized to RNU6 (cat. no: 4427975/assay ID: 001973) for each cell line using a cycle threshold of 0.1 to calculate $\Delta \mathrm{Cq}$ values for analysis using the comparative $\Delta \Delta \mathrm{Cq}$ method (20). All reactions were completed in duplicate.

Bioinformatic analysis. Targets of the miR-200 family were screened using Ingenuity Pathway Analysis (Qiagen, Hilden Germany.) This program uses publicly available datasets and the scientific literature to identify dysregulated pathways in diseases and potential gaps in molecular signaling. The identified molecular interactions were investigated and verified using mirTarBase (21). The predicted binding between the miR-200 family and RASSF2 has previously been experimentally verified using dual-luciferase reporter assay and Northern blotting (22). The results of this study demonstrate the direct binding interaction between the miR-200 family and RASSF2.

The Cancer Genome Atlas and microarray datasets. The RNA-seq expression data for RASSF2 and microRNA-seq expression data for the miR-200 family in patients with colon adenocarcinoma was downloaded from cbioportal (http://www.cbioportal.org/accessed 10/01/2018). The microRNA-seq expression data for the same patients with colon adenocarcinoma was downloaded from Firebrowse (http://firebrowse.org/ accessed 11/20/18). The associated clinical dataset was downloaded from The Cancer Genome Atlas (TCGA, https://portal.gdc.cancer.gov/). The GSE115513 microarray normalized dataset was downloaded from Gene Expression Omnibus. The paired tumor and normal adjacent tissue datasets were extracted.

Reverse transcription $(R T)$ and quantitative real-time polymerase chain reaction ( $R T-q P C R)$. Isolation of total RNA from cell lysates was performed using the Ambion ${ }^{\circledR}$ miRVana miRNA isolation kit (Life Technologies). Quantitation of total RNA quantity and quality was determined using a Nanodrop 2000 spectrophotometer (ThermoFisher Scientific,'Inc.). Complementary DNA (cDNA) was generated from $10 \mathrm{ng}$ total RNA samples using the TaqMan ${ }^{\circledR}$ miRNA reverse transcription kit (Life Technologies). qPCR was performed using $1.33 \mu \mathrm{l}$ of cDNA and TaqMan ${ }^{\circledR}$ microRNA assays (Life Technologies). Reactions were run in duplicate.

$m R N A$ quantification. For mRNA quantification, total RNA was converted to cDNA using a high-capacity cDNA reverse transcription kit (Life Technologies) with random nucleotide primers. Specific TaqMan ${ }^{\circledR}$ probes for RASSF2 (cat. no: 4331182/Hs00248129_m1) and 18S (cat. no: 4331182/Hs03928990_g1) (endogenous internal 
reference gene) were used during RT-qPCR. All reactions were completed in duplicate. Nucleic acid quantification was performed using a Step-One Plus RT-qPCR system (Life Technologies). The expression levels of RASSF2 mRNA were normalized to $18 \mathrm{~S}$ using a cycle threshold of 0.1 to calculate $\Delta \mathrm{Cq}$ values for analysis using the comparative $\Delta \mathrm{Cq}$ method.

miRNA transfection. Each cell line was transfected with each individual member of the miR-200 family. Scrambled oligonucleotides served as a negative control using mirVana ${ }^{\mathrm{TM}}$ miRNA mimics (for CCD-841 CoN) and antagomirs (for HT-29) (Life Technologies). Once plated, cells were allowed a 24-h acclimation period to adhere to the plate prior to transfection. After $24 \mathrm{~h}$, when cells were $60-80 \%$ confluent in each well, they were transfected using Lipofectamine ${ }^{\circledR}$ RNAiMAX transfection reagent (Life Technologies), according to the manufacturer's protocol.

Immunoblotting. Cells were lysed using radio immune-precipitation assay (RIPA) buffer and the protein concentration determined using the bicinchoninic acid (BCA) assay. Forty micrograms of total protein from each cell lysate was separated by NuPAGE ${ }^{\circledR}$ MOPS SDS and transferred on to a nitrocellulose membrane. The primary antibodies used were RASSF2 EPR6621 (1:1,000; Abcam) and $\beta$-actin (1:10,000; Cell Signaling Technology). Secondary antibodies used were HRP-conjugated goat anti-rabbit and horse anti-mouse IgG (1:1,000; Cell Signaling Technology). The membrane was incubated in equal parts of enhanced chemiluminescence (ECL) reagents $\mathrm{A}$ and $\mathrm{B}$ for $5 \mathrm{~min}$ in the dark to detect the target protein, and then developed and imaged using a ChemiDoc MP imager (BioRad, Hercules, CA, USA).

Enzyme-linked immunosorbent assay. Cells were seeded in 6 -well plates $(250,000$ cells/well) and transfected as previously described. After $24 \mathrm{~h}$, cell sample lysates were harvested with cell lysis mix and protein concentration determined using the BCA assay. Fifty microliters of cell lysate and $50 \mu 1$ of pre-prepared antibody cocktail mix were added into an InstantOne $^{\mathrm{TM}}$ ELISA 96 well plate (Affymetrix, Santa Clara, CA, USA), according to the manufacturer's protocol. Total and phosphorylated ERK1/2 levels were measured by reading the absorbance of the samples using the SPECTRAmax ${ }^{\circledR}$ PLUS 384 microplate spectrophotometer at a wavelength of $450 \mathrm{~nm}$.

Cell proliferation assay. HT-29 and CCD-841 CoN cells were plated in duplicate at a concentration of $100,000 \mathrm{cells} / \mathrm{ml}$ and 50,000 cells $/ \mathrm{ml}$ in individual wells in 12 -well plates, respectively. After $24 \mathrm{~h}$, cells were serum-starved in $0.5 \%$ FBS for $2 \mathrm{~h}$ before replacement of normal growth medium and then transfected with miRNA mimics and antagomirs as previously described. Transfection was stopped after $24 \mathrm{~h}$, and cells were trypsinized. A $10 \mu \mathrm{l}$ sample from each well was inserted into a dual chamber counting slide (Bio-Rad), and the cell number was measured daily for 5 days using an automated cell counter (TC20 ${ }^{\mathrm{TM}}$, Bio-Rad).

Human tissue. Fresh frozen tissue samples of colon cancer and normal adjacent colon epithelial tissue, which was taken at least $10 \mathrm{~cm}$ from the primary lesion from five patients diagnosed with stage III adenocarcinoma were obtained from the University of Louisville surgical biorepository.
Laser capture microdissection. Tissue serial sections were cut at $7-\mu \mathrm{m}$ thickness, mounted, and stained using the Histogene ${ }^{\mathrm{TM}}$ LCM frozen section staining kit. One slide stained with hematoxylin and eosin per sample was used as reference. Colon cancer and normal adjacent colon epithelial tissue were identified and laser captured using the ArcturusXT ${ }^{\mathrm{TM}}$ laser capture microdissection system. RNA was extracted and isolated using the Arcturus ${ }^{\circledR}$ PicoPure ${ }^{\circledR}$ frozen RNA isolation kit. RT and RT-qPCR for the miR-200 family and RASSF2 was performed. Protein was extracted and RASSF2 measured via western blot analysis as previously described.

Statistical analysis. For each cell line and transfected miRNA, samples were prepared in replicates of five unless otherwise stated. Cell culture samples were grown from new freezes and transfected at the same passage to maintain a true sample size of five. All reactions were run in duplicate, and averages of the duplicates were used for analysis. The chi-squared test or Fischer exact test, where appropriate, were used to compare categorical variables. The independent Student's t-test or Mann-Whitney U test was used to compare continuous non-paired variables. The difference in paired continuous data was done with the Wilcoxon signed-rank test. For tests with multiple comparisons, a repeated measures analysis of variance with post hoc Bonferroni correction was performed. The difference in overall and recurrence-free survival were assessed by Kaplan-Meier survival analysis and the log rank test. Univariable and multivariable Cox regression analyses were done to identify risk factors for a reduced overall survival. Correlation between mRNA and miRNA expression was analyzed with Spearman Rank correlation test. Statistical analysis was performed using the Statistical Package for the Social Sciences (SPSS) v25.0 (IBM Corp, Armonk, NY, USA). Graphs were prepared using GraphPad Prism v6.01 (GraphPad Software, Inc., La Jolla, CA, USA). P $<0.05$ was considered to indicate a statistically significant difference. Data are presented as mean \pm standard deviation (SD).

\section{Results}

miR-200 family expression is increased in colorectal cancer and is increased in localized cancer compared with metastatic cancer

In vitro studies. To verify that the miR-200 family was upregulated in an in vitro model, we screened for the expression of 384 miRNAs, using TLDA miRNA arrays cards in the human colon adenocarcinoma cell lines HT-29 and T-84 compared with a normal colon epithelial (CCD-841 CoN) cell line (Fig. 1). The miR-200 family was the most significantly upregulated. As the HT-29 cell line showed the greatest differential expression of the miR-200 family as compared with the normal colon epithelial cell line and is known to demonstrate an epithelial phenotype (23), it was chosen for further study. These data were confirmed on single assay analysis. Comparison between the HT-29 and CCD-841 CoN cell lines showed elevated levels of miR-200a, miR-200b, miR-200c, miR-141, and miR-429 in HT-29 samples $(\mathrm{P}<0.0001$; Fig. 2A). miR-200 family expression in cells was increased or suppressed by transfection with individual miRNA mimics $(\mathrm{CCD}-841 \mathrm{CoN})(\mathrm{P}<0.001)$ or antagomirs (HT-29) [miR-200b $\mathrm{P}<0.01, \mathrm{miR}-200 \mathrm{c} \mathrm{P}<0.001$, (Fig. 2B and C)]. 


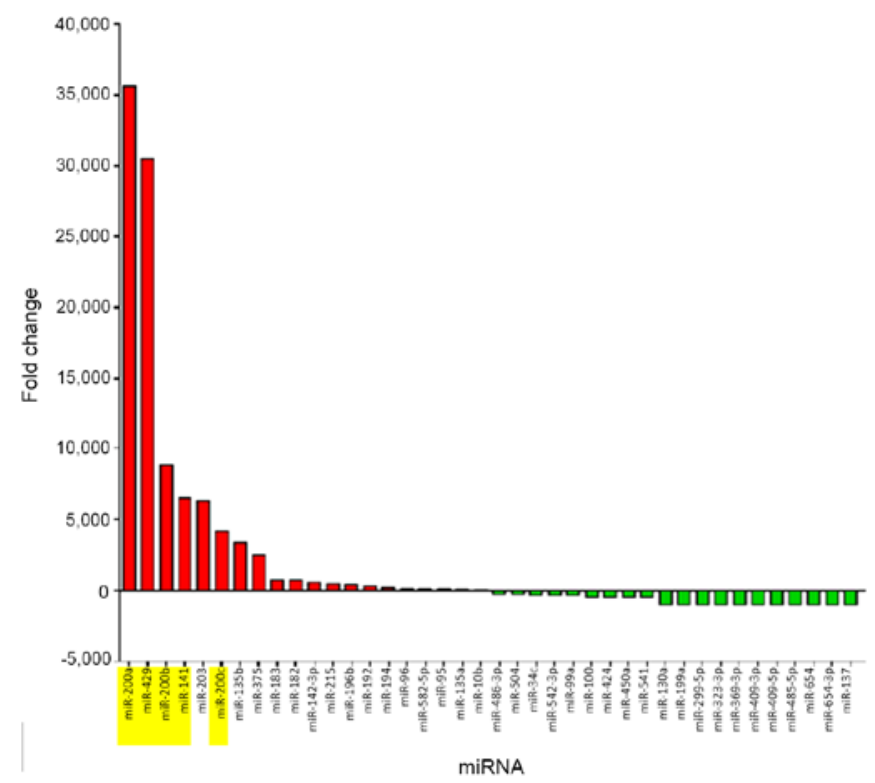

Figure 1. Waterfall plot of the significantly dysregulated miRs in colon cancer cell lines HT-29 and T-84 as compared to the normal colon epithelial cell line (CCD-841). miR200 family is highlighted in yelow. miR, microRNA.

Studies using data from human biorepositories. Using the paired microRNA microarray GSE115513 dataset $(n=632)$, all members of the miR-200 family were increased in colorectal cancer compared with paired normal adjacent colon epithelium (all $\mathrm{P}<0.001$; Fig. 3). As the miR-200 family is known to have a role in cancer progression, the miR-200 family expression was examined between localized (stage I and II) and metastatic (stage III and IV) colon adenocarcinoma microRNA-seq dataset derived from TCGA [(n=229); Fig. 3]. Using the median expression as a cut-off, miR-200a $(\mathrm{P}=0.006)$, miR-200c $(\mathrm{P}<0.001)$, and miR-141 $(\mathrm{P}=0.003)$ were all significantly increased in localized cancer compared with metastatic cancer. Additionally, miR-200b $(\mathrm{P}=0.06)$ and miR-429 $(\mathrm{P}=0.08)$ had a significant trend towards increased expression in localized cancer compared with metastatic cancer. As expected, low miR-200a $(\log -\mathrm{rank}=0.02)$, mirR-200b (log-rank=0.05), and miR-200c $(\log -\mathrm{rank}=0.03)$ expression were significantly associated with worse overall survival. miR-429 $(\mathrm{P}=0.61)$ and miR-141 $(\mathrm{P}=0.30)$ were not associated with worse overall survival (Fig. 3). Low cancer tissue miR-200a, low miR-200b, and low miR-200c expression were significantly associated with advanced stage disease (Table I). On univariable and multivariable analysis, low tumor miR-200a, low miR-200b, and low miR-200c were all significant predictors of shorter overall survival (Table II). Individual multivariable Cox regression models were used due to the expected significant collinearity between members of the miR-200 family.

miR-200 family targets the tumor suppressor RASSF2. Utilizing microarray screening data, Ingenuity Pathway Analysis (Qiagen, Hilden, Germany) identified relevant miRNAs and associated pathways. The MAPK/ERK signaling pathway was the pathway most closely linked to the colon cancer cell line screening data. All members of the miR-200 family were significantly enriched within this pathway (Fig. S1). miRTarBase identified all five miR200 family miRNAs (miR-200a, miR-200b, miR-200c, miR-141, miR-429) to target the same gene, RASSF2. The
miR-200 family previously has been demonstrated to directly bind RASSF2 using dual-luciferase reporter assay and Northern blotting (22). Expression of all members of the miR-200 family was significantly inversely correlated with that of RASSF2 using TCGA dataset (Fig. 4). Decreased RASSF2 expression was associated with a trend towards a worse recurrence-free survival ( $\mathrm{P}=0.058$; Fig. 5).

miR-200 family expression can regulate RASSF $2 \mathrm{mRNA}$ expression. RASSF2 mRNA expression was significantly decreased in HT-29 cells as compared with CCD-841 CoN (fold regulation $-6282, \mathrm{P}<0.001$ ). Knock down of the miR-200 family in HT-29 cells led to increased RASSF2 mRNA expression in the HT-29 cell line significantly for miR-429 with a fold change of 3.82 ( $\mathrm{P}<0.001$; Fig. 6A). Overexpression of the miR-200 family in CCD-841 CoN cells led to a decreased RASSF2 mRNA expression. miR-200a and miR-200b mimics significantly downregulated RASSF $2 \mathrm{mRNA}$ (fold regulation= $-1.45, \mathrm{P}=0.01$, and fold regulation $=-1.74, \mathrm{P}<0.001$; Fig. $6 \mathrm{~B}$ ).

miR200 family expression can regulate RASSF2 protein expression. The change in RNA expression was verified by examining RASSF2 protein expression. RASSF2 protein was present in CCD-841 CoN cells, whereas no RASSF2 protein was detected in the HT-29 cell line (Fig. 7A and B). Transfection with miR-200 family member mimics led to a decreased trend in RASSF2 protein expression in the CCD-841 CoN cell line. RASSF2 protein levels were significantly lower in CCD-841 CoN cells when transfected with miR-200a, miR-200b, miR-429 mimics ( $\mathrm{P}<0.05$; Fig. 7C). Increased expression of RASSF2 protein expression was observed in the HT-29 cell line with transfection of miR-141 and miR-429 antagomirs $(\mathrm{P}<0.05$; Fig. 7D).

miR-200 family can regulate activity in the MAPK/ERK pathway. Transfection with miR-200 family mimics led to an increased trend in KRAS protein expression in the CCD-841 CoN cells. There were significant increases observed with miR-200a, miR-141, and miR-429 (P<0.05; Fig. 8A). Transfection with miR-200 family antagomirs led to KRAS protein in the HT-29 cells, and there were significant increases observed with miR-200a and miR-200c knockdown $(\mathrm{P}<0.05$; Fig. 8B). The normalized expression of KRAS in the HT-29 cells was 10 -fold lower than that of the CCD-841 cells, which suggests there was low endogenous expression of KRAS. Subsequent activity within the MAPK pathway was measured by ERK phosphorylation compared with total ERK1/2 levels. There was an increased ratio of phosphorylated-to-total ERK $1 / 2$ with transfection of miR-200 family mimics in the CCD-841 cell line (all $\mathrm{P}<0.01$; Fig. 9A). There was a decreased trend in the ratio of phosphorylated-to-total ERK1/2 in the HT-29 cell line with transfection of miR-200 family antagomirs. There was a significant decrease in the ratio of phosphorylated-to-total ERK1/2 with transfection of miR-200a, miR-200b, and miR-141 antagomirs $(\mathrm{P}<0.05$; Fig. 9B). These results indicate that the miR-200 family can regulate MAPK/ERK pathway activation, in part, through KRAS regulation.

miR-200 family expression can regulate cell proliferation. As the MAPK/ERK pathway is a major regulator of 

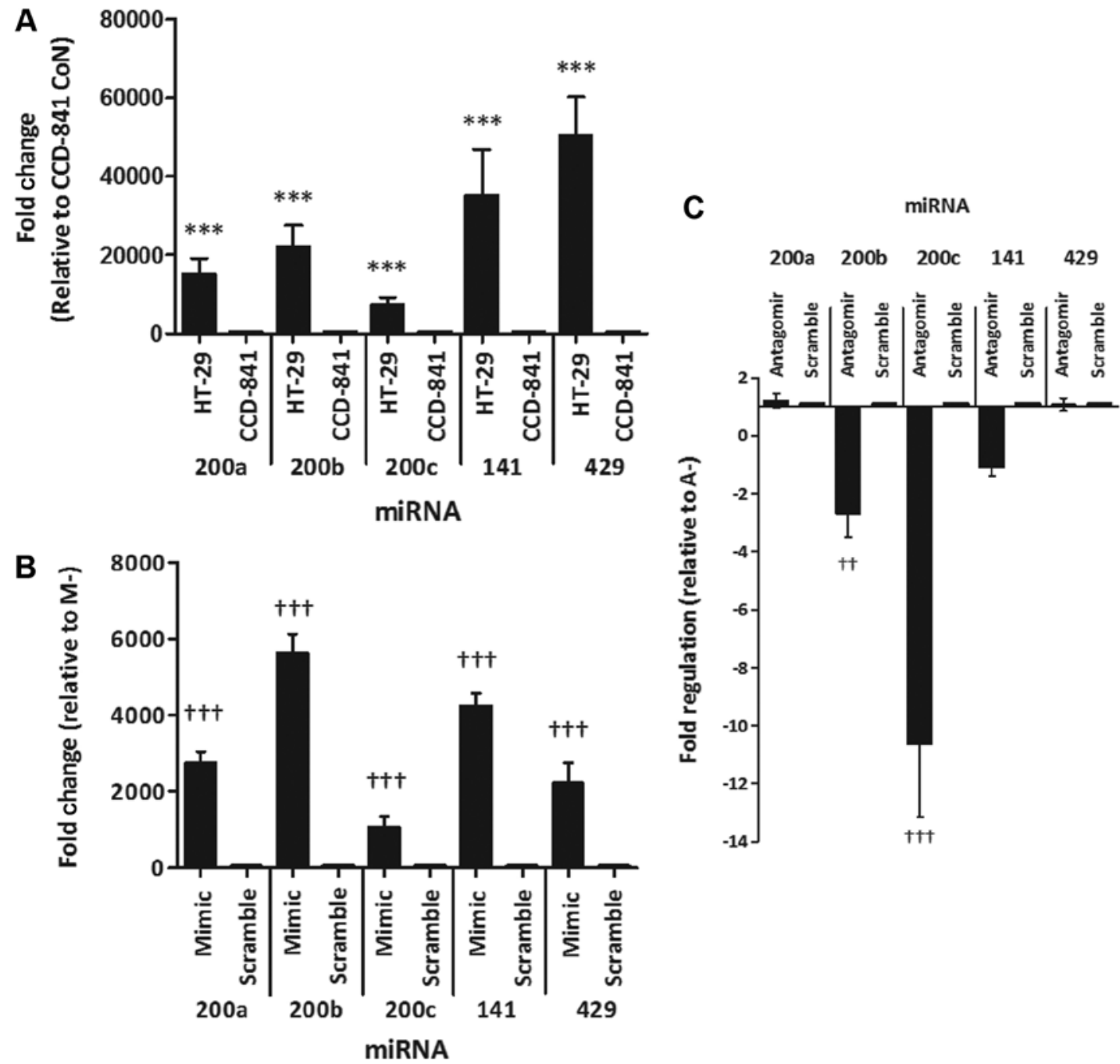

Figure 2. Baseline miR-200 family expression and expression post transfection with miR-200 mimics and antagomirs. (A) Significant upregulation of all members of the miR-200 family in the HT-29 cell line vs. the CCD-841 cell line. (B) Significant upregulation of all of the miR-200 family compared to scramble following transfection with individual miR-200 family mimics in the CCD-841 cell line. (C) Significant downregulation of miR-200b and miR-200c following transfection with antagomirs as compared with scramble in the HT-29 cell line. ${ }^{* * *} \mathrm{P}<0.0001$ vs. CCD-841; ${ }^{\dagger \dagger} \mathrm{P}<0.01$ and ${ }^{\dagger \dagger} \mathrm{P}<0.001$ vs. scramble. miR, microRNA.

cellular growth, cell proliferation was measured to analyze the functional effect of MAPK/ERK pathway regulation by the miR-200 family. Transfection with miR-200a, miR-200c, and miR-141 mimics led to increased cell proliferation in CCD-841 cells $(\mathrm{P}<0.05$; Fig. 9C). Transfection with miR-200 antagomirs led to decreased cell proliferation in HT-29 cells (all P<0.001; Fig. 9D).

Laser capture microdissection of colon cancer tissue for miR-200 family, RASSF 2 mRNA, and RASSF 2 protein expression. A laser capture microdissection system was used to selectively dissect paired cancer tissue and normal epithelium from patients with stage III colon adenocarcinoma (Fig. 10A). There was downregulation of miR-200a $(\mathrm{P}=0.047), \mathrm{miR}-200 \mathrm{~b}$ ( $\mathrm{P}=0.119)$, miR-141 ( $\mathrm{P}=0.007)$, and miR-429 $(\mathrm{P}=0.027)$, with no difference in miR-200c $(\mathrm{P}=0.589)$ in colon cancer tissue samples compared with normal adjacent epithelium (Fig. 10B). These results reflect the data seen in the previous sequencing datasets, where the miR-200 family was downregulated in metastatic disease. There was a 2.7 -fold downregulation of
RASSF2 mRNA in the cancer tissue compared with colon epithelium ( $\mathrm{P}=0.021$; Fig. 10C), and a 6-fold downregulation of RASSF2 protein in colon cancer tissue relative to normal adjacent epithelium ( $\mathrm{P}=0.092$; Fig. 10D).

\section{Discussion}

This study describes the role of the miR-200 family in the regulation of RASSF2 and the subsequent downstream effect upon the MAPK/ERK signaling pathway. All members of the miR-200 family were significantly increased in colon cancer tissue compared with paired normal adjacent colon epithelium. Interestingly, there was a progressive decrease in miR-200 family expression in metastatic colon cancer compared with localized cancer. The significance of the miR-200 family in colon cancer was further highlighted in a screening miRNA array, where it was the most upregulated group of miRNA compared with normal colon cells. Pathway analysis software and a previous study identified that the miR-200 family directly binds RASSF2 (22). We further demonstrated this by showing 
A

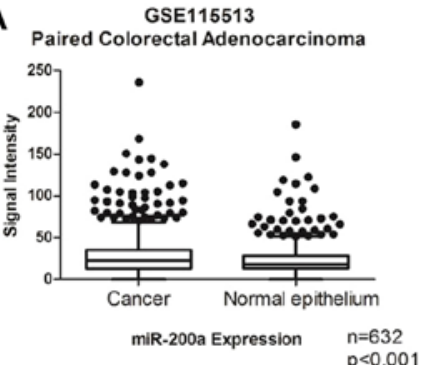

D

Paired Colorectal Adenocarcinoma

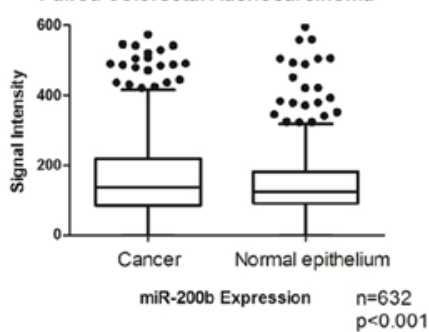

G
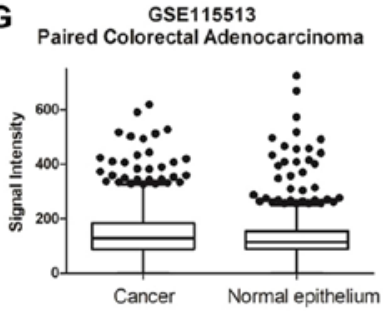

miR-200c Expression $\quad \mathrm{n}=632$
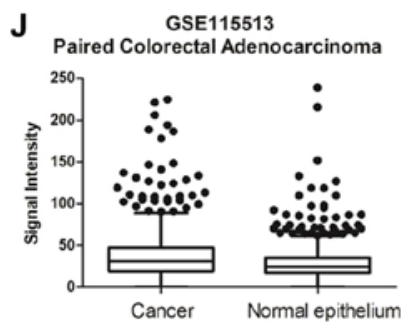

$\begin{array}{ll}\text { miR-141 Expression } & n=632 \\ & p<0.001\end{array}$
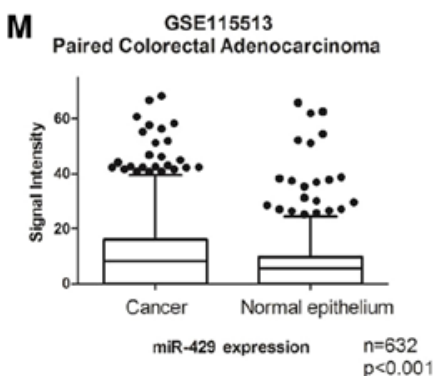

B Difference in miR-200a expression between localized and metastatic colon adenocarcinoma

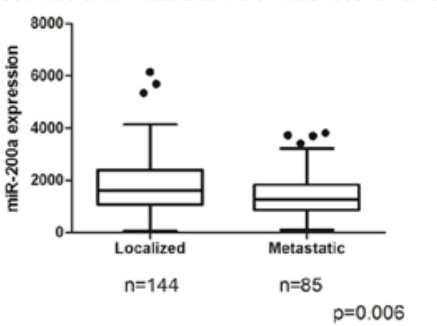

E Difference in miR-200b expression between localized and metastatic colon adenocarcinoma

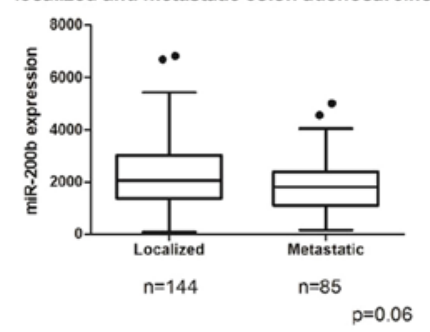

H Difference in miR-200c expression between localized and metastatic colon adenocarcinoma

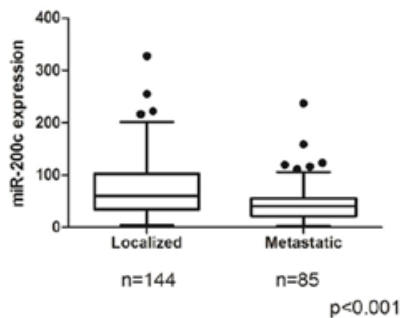

K Difference in miR-141 expression between localized and metastatic colon adenocarcinoma

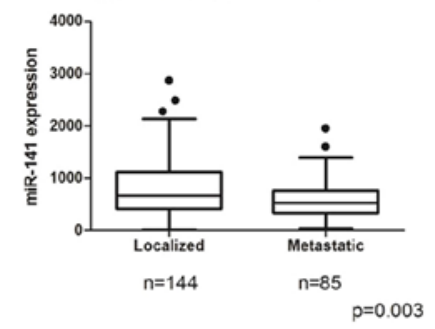

N Difference in miR-429 expression between localized and metastatic colon adenocarcinoma

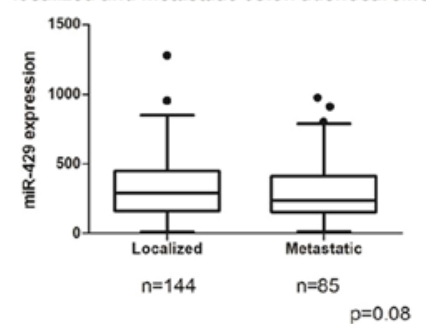

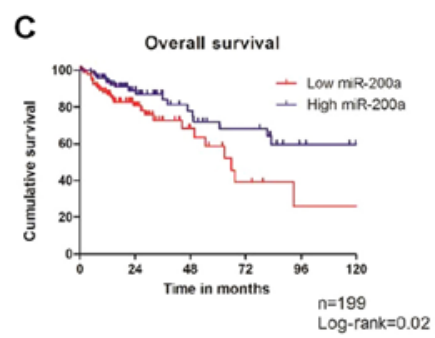

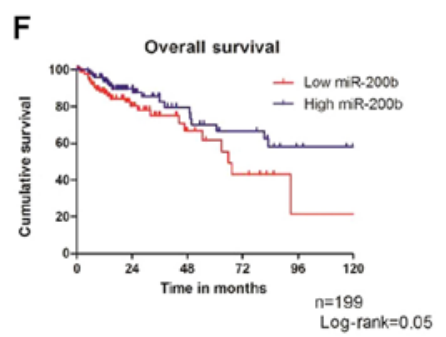

I

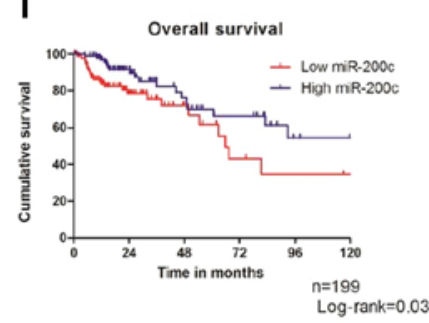

L

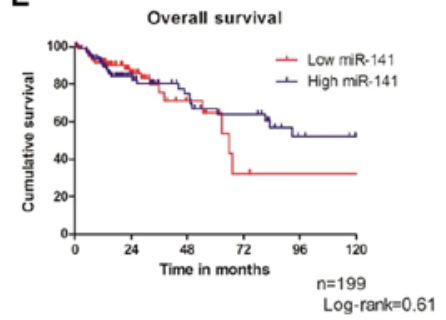

$\mathbf{O}$

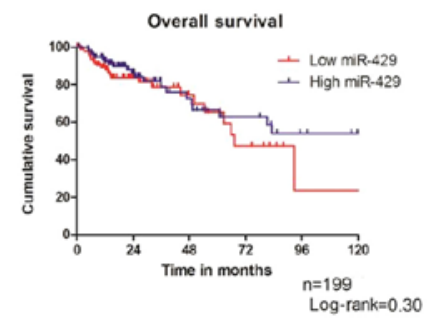

Figure 3. (A-C) miR-200a is increased in cancer tissue compared with normal adjacent epithelium $(\mathrm{P}<0.001)$. miR-200a expression is decreased in advanced stage (stage III or IV) compared with localized disease (stage I or II, P=0.006.) Low expression of miR-200a is associated with worse overall survival (log-rank=0.02). (D-F) miR-200b is increased in cancer tissue compared to normal adjacent epithelium (P<0.001). miR-200b expression is decreased in advanced stage (stage III or IV) compared to localized disease (stage I or II) $(\mathrm{P}=0.06)$. Low expression of miR-200b is associated with worse overall survival (log-rank=0.05). (G-I) miR-200c is increased in cancer tissue compared to normal adjacent epithelium $(\mathrm{P}<0.001)$. miR-200c expression is decreased in advanced stage (stage III or IV) compared to localized disease (stage I or II, $\mathrm{P}<0.001$ ). Low expression of miR-200c is associated with worse overall survival (log-rank=0.03). ( J-L) miR-141 is increased in cancer tissue compared to normal adjacent epithelium $(\mathrm{P}<0.001)$. miR-141 expression is decreased in advanced stage (stage III or IV) compared to localized disease (stage I or II, $\mathrm{P}=0.003$ ). No difference in the overall survival between high and low miR-141 (log-rank=0.61). (M-O) miR-429 is increased in cancer tissue compared to normal adjacent epithelium $(\mathrm{P}<0.001)$. miR-429 expression is decreased in advanced stage (stage III or IV) compared to localized disease (stage I or II, $\mathrm{P}=0.08$ ). No difference in the overall survival between high and low miR-429 $(\log$-rank=0.30). miR, microRNA. 
Table I. Clinicopathological variables for patients with colon adenocarcinoma in the Cancer Genome Atlas dataset.

\begin{tabular}{|c|c|c|c|}
\hline Variables & Total $(n=199)$ & Localized disease $(n=114)$ & Metastatic disease $(n=85)$ \\
\hline Age, years (median, IQR) & $66(56-75)$ & $69(58-77)$ & $64(52-73)$ \\
\hline \multicolumn{4}{|l|}{ Sex } \\
\hline Male & $112(56)$ & $67(59)$ & $45(53)$ \\
\hline Female & $87(44)$ & $47(41)$ & $40(47)$ \\
\hline \multicolumn{4}{|l|}{ Race } \\
\hline Caucasian & $162(85)$ & $93(86)$ & $69(83)$ \\
\hline African-American & $29(15)$ & $15(14)$ & $14(17)$ \\
\hline \multicolumn{4}{|l|}{ Anatomical location } \\
\hline Cecum & $54(29)$ & $29(27)$ & $25(31)$ \\
\hline Ascending colon & $38(2)$ & $26(24)$ & $12(15)$ \\
\hline Hepatic flexure & $13(7)$ & $6(6)$ & $7(9)$ \\
\hline Transverse colon & $14(7)$ & $8(7)$ & $6(7)$ \\
\hline Splenic flexure & $4(2)$ & $3(3)$ & $1(1)$ \\
\hline Descending colon & $10(5)$ & $5(5)$ & $5(6)$ \\
\hline Sigmoid colon & $56(30)$ & $30(28)$ & $26(32)$ \\
\hline \multicolumn{4}{|l|}{ Lymphatic invasion } \\
\hline Yes & $48(27)$ & $7(7)$ & $41(55)$ \\
\hline No & $130(73)$ & $96(93)$ & $34(45)$ \\
\hline \multicolumn{4}{|l|}{ Venous invasion } \\
\hline Yes & $38(22)$ & $7(7)$ & $44(59)$ \\
\hline No & $137(78)$ & $93(93)$ & $31(41)$ \\
\hline \multicolumn{4}{|l|}{ Perineural invasion } \\
\hline Yes & $36(29)$ & $15(21)$ & $21(39)$ \\
\hline No & $88(71)$ & $55(79)$ & $33(61)$ \\
\hline \multicolumn{4}{|l|}{ miR-200a } \\
\hline Low & $100(50)$ & $49(43)$ & $51(60)$ \\
\hline High & $99(50)$ & $65(57)$ & $34(40)$ \\
\hline \multicolumn{4}{|l|}{ miR-200b } \\
\hline Low & $100(50)$ & $51(45)$ & $49(58)$ \\
\hline High & $99(50)$ & $63(55)$ & $36(42)$ \\
\hline \multicolumn{4}{|l|}{ miR-200c } \\
\hline Low & $100(50)$ & $45(40)$ & $55(65)$ \\
\hline High & $99(50)$ & $69(60)$ & $30(35)$ \\
\hline \multicolumn{4}{|l|}{ miR-141 } \\
\hline Low & $100(50)$ & $47(41)$ & $53(62)$ \\
\hline High & $99(50)$ & $67(59)$ & $32(38)$ \\
\hline \multicolumn{4}{|l|}{$\operatorname{miR}-429$} \\
\hline Low & $100(50)$ & $53(47)$ & $47(55)$ \\
\hline High & $99(50)$ & $61(54)$ & $38(45)$ \\
\hline
\end{tabular}

Categorical data expressed as N (\%). Continuous data compared using Mann-Whitney U test. Categorical data compared using $\chi^{2}$ test. Boldface shows significant difference. IQR, Interquartile Range.

a significant inverse correlation between all members of the miR-200 family and RASSF2. Transfection with miR-200 family mimics, and antagomirs could regulate cell proliferation, in part, by directly regulating RASSF2 expression and subsequently increasing MAPK/ERK pathway signaling through KRAS.
Although miR-200 family knockdown led to an increased trend in RASSF2 expression and induced activation of the MAPK/ERK signaling pathway, it increased KRAS expression in the HT-29 cell line. This discrepancy can be explained, as the miR-200 family have a number of different target molecules, and KRAS has a number of upstream regulators. 


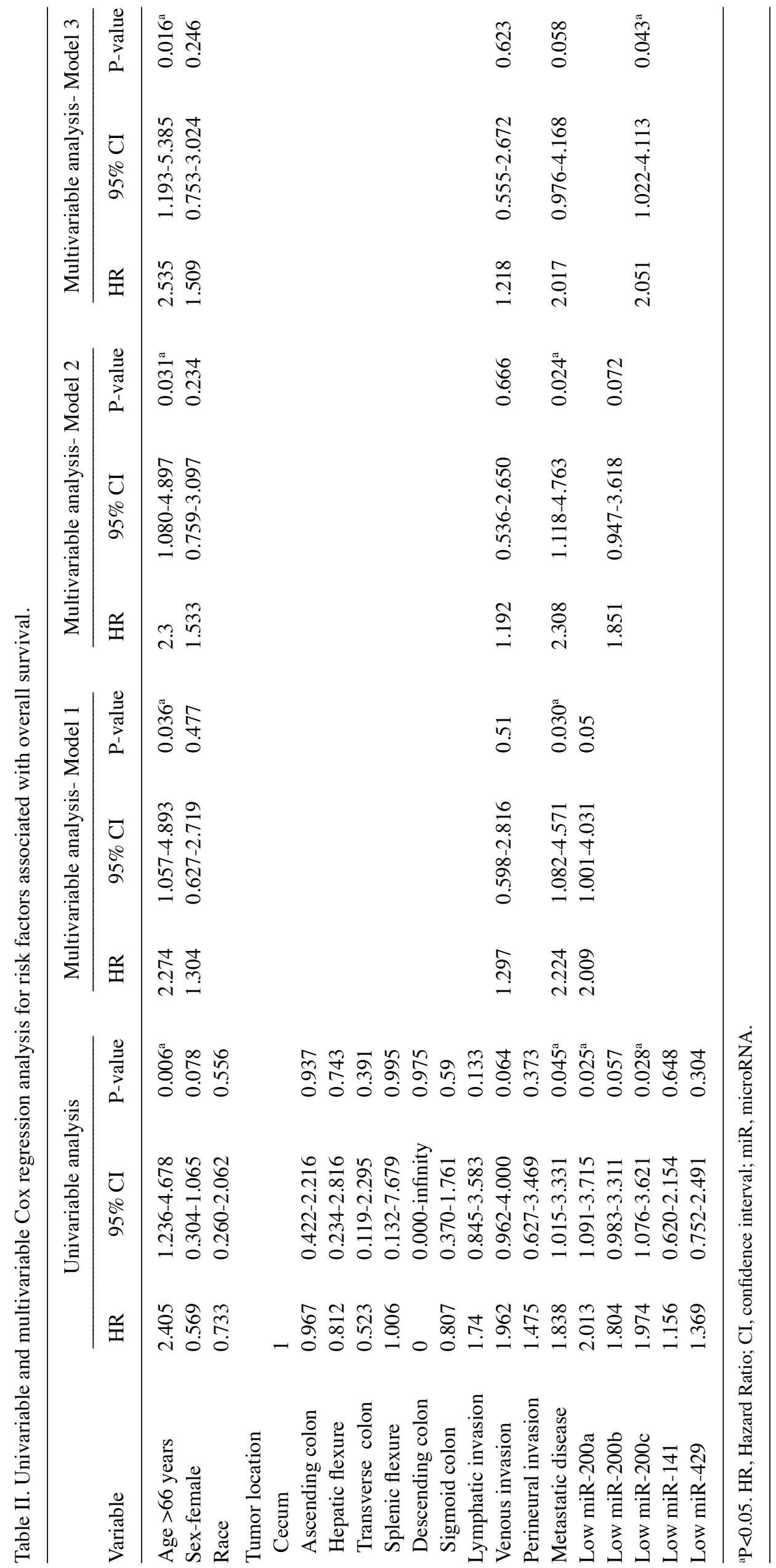



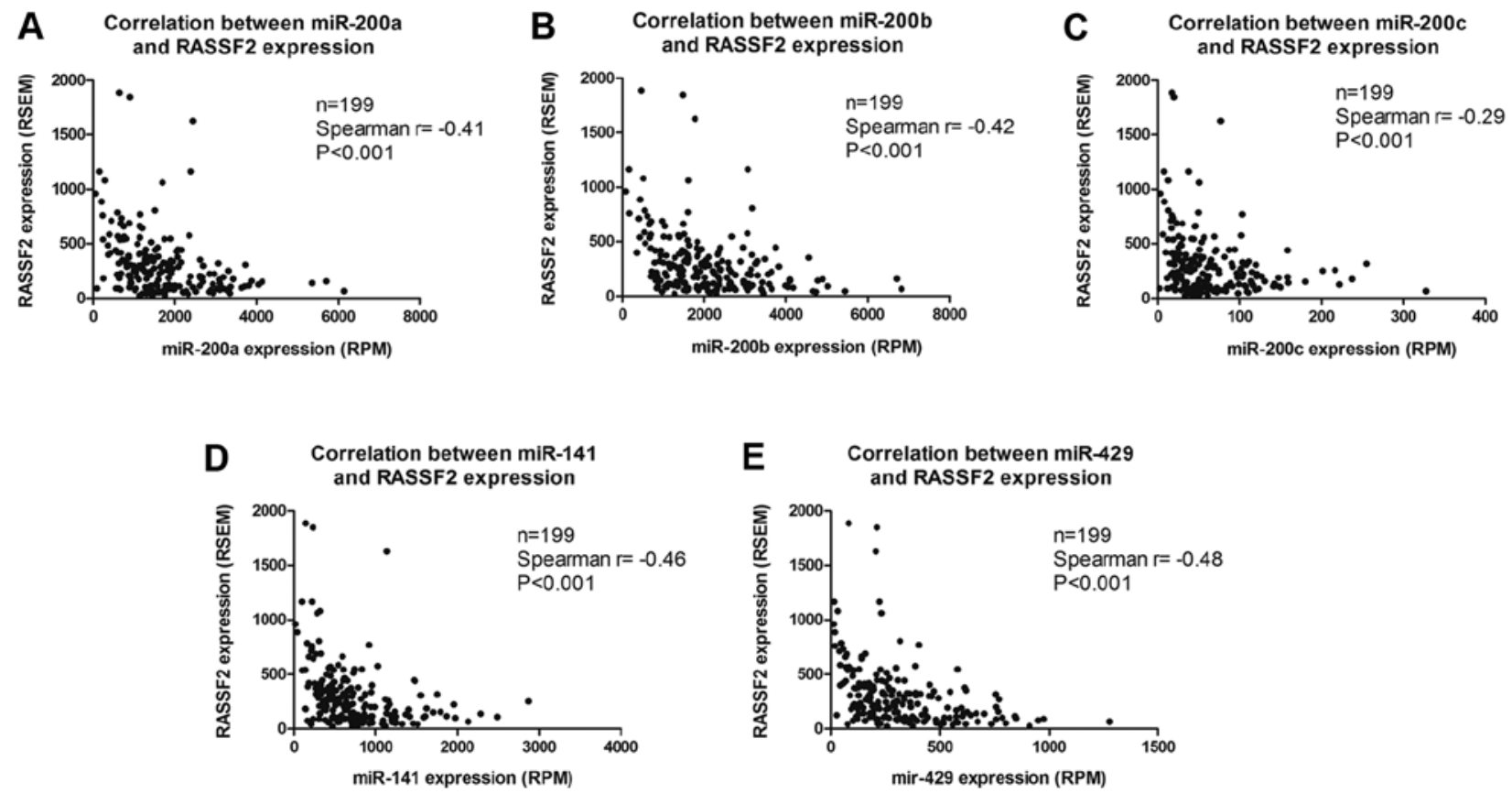

Figure 4. Correlation of miR-200 family expression with RASSF2 expression in the colon adenocarcinoma TCGA dataset. (A-E) The miR-200 family is significantly inversely correlated with RASSF2 expression $(n=199, \mathrm{P}<0.001)$. miR, microRNA.

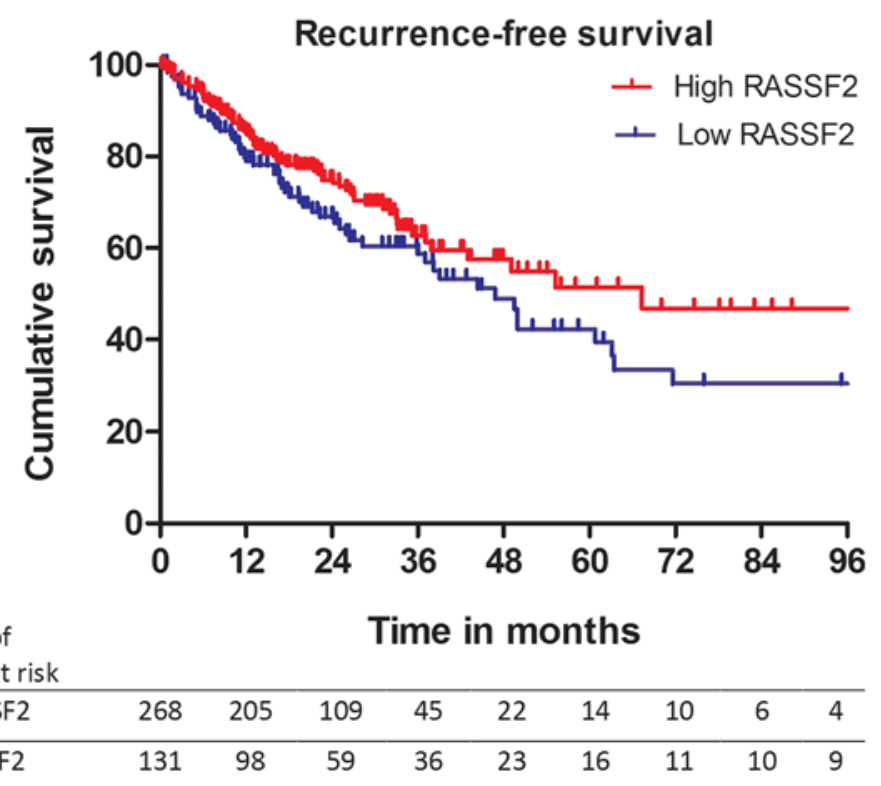

Figure 5. Reduced expression of RASSF2 was associated a trend towards worse recurrence-free survival (log-rank=0.058).

Knockdown of the miR-200 family can induce ZEB1 expression, which can, in turn, induce KRAS expression (24). Previous studies have demonstrated an inverse relationship between miR-200 family members and KRAS expression in certain cancers $(24,25)$. In a number of breast cancer cell lines, miR-200c expression was inversely proportional to KRAS expression (25). Despite these results, the miR-200 family knockdown decreased ERK phosphorylation in the MAPK/ERK signaling cascade.

This study did not make a direct comparison between the cell lines, but there was an approximately 10 -fold increase in the expression KRAS in the CCD-841 cells compared with the HT-29 cells. This is likely suggestive of either low endogenous KRAS expression in the HT-29 cell line or the miR-200 family is mediating its effect, in part, through another signaling cascade (26). All members of the miR-200 family also could be decreasing cellular proliferation, which was found to be mediated through MAPK/ERK signaling.

An apparent discrepancy in the miR-200 family expression between the cell line comparison data and the human tissue data can be explained by the microarray and TCGA data. The miR-200 family expression was increased in cancer tissue compared with paired normal adjacent tissue, but the data from the miRNA-seq indicated that there was decreased expression in metastatic cancer compared with localized 

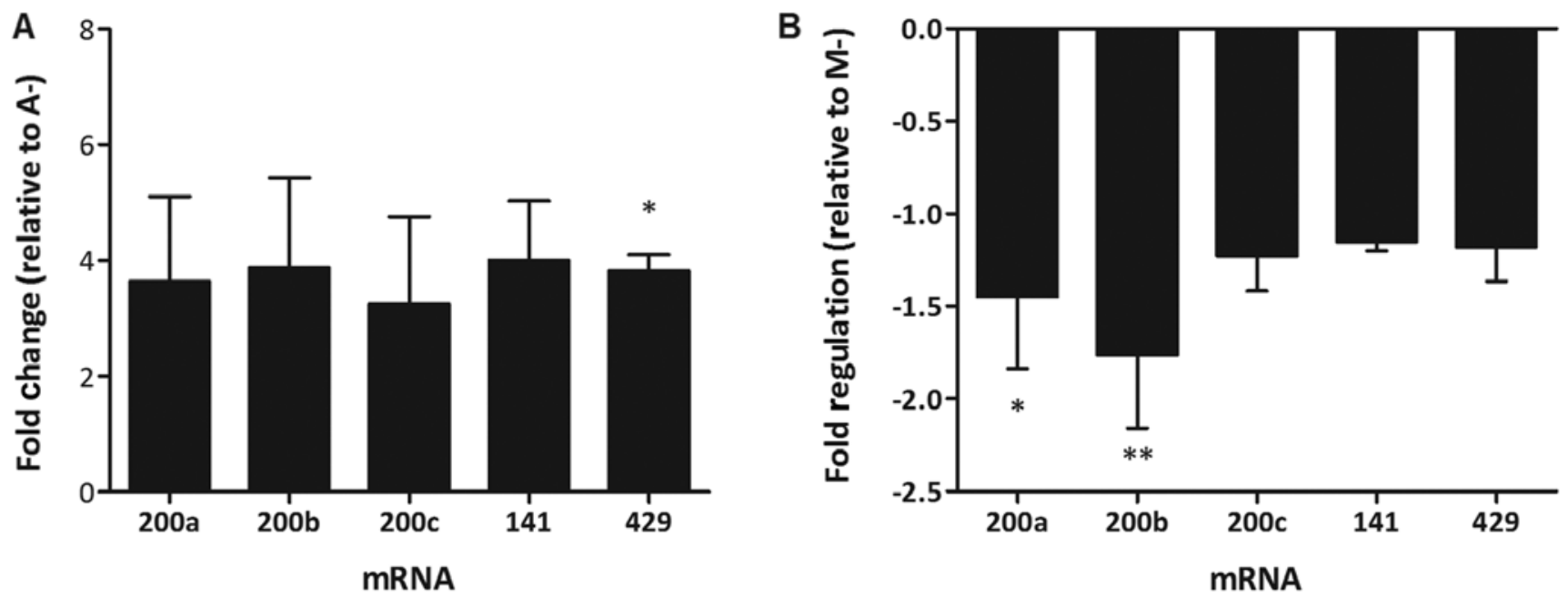

Figure 6. Expression of RASSF2 mRNA following transfection with miR-200 mimics and with miR-200 antagomirs. (A) Increased trend in the expression of RASSF2 in the HT-29 cell line following transfection with miR-200 antagomirs as compared with scramble (A-). "P=0.01. (B) Decreased trend in the expression of RASSF2 mRNA in the CCD-841 cell line following transfection with miR-200 mimics as compared with scramble (M-). ${ }^{*} \mathrm{P}=0.01$ and ${ }^{* * *} \mathrm{P}<0.001$ vs. scramble. miR, microRNA.
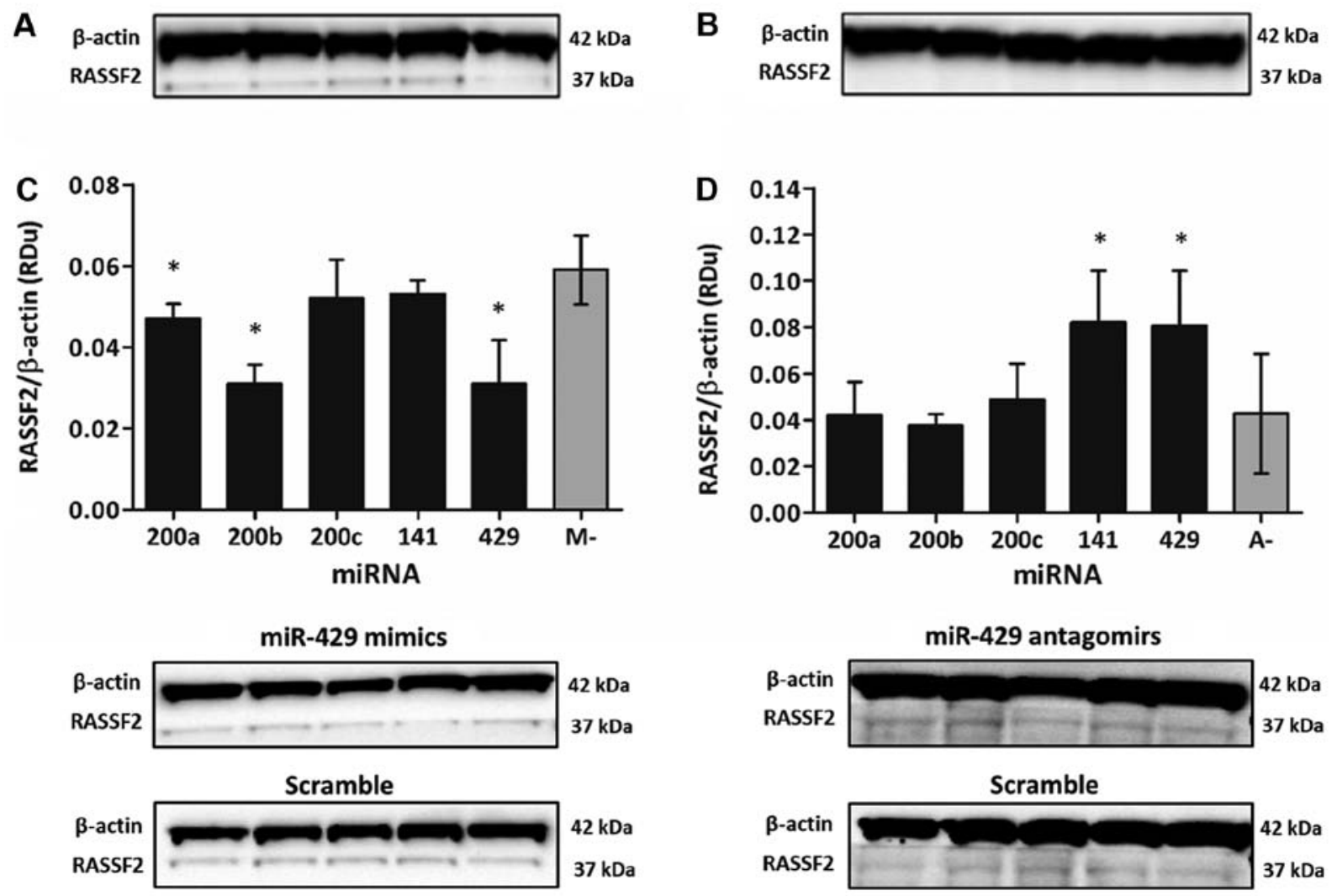

Figure 7. Baseline RASSF2 protein expression and following transfection miR-200 mimics or antagomirs. (A) RASSF2 protein is expressed in the CCD-841 cell line at baseline. (B) There is no RASSF2 protein expression in the HT-29 cell line at baseline. (C) Following transfection with miR-200 mimics, there is reduced expression of RASSF2 protein compared to scramble with miR-200a, miR-200b, and miR-429 ("P<0.05 vs. scramble). Histograms are representative of $n=5$ experimental repeats for all transfections. Representative blots demonstrating significant decrease in RASSF2 expression following transfection with miR-429 mimics compared to scramble. (D) Following transfection with miR-200a and miR-200c antagomirs, there was an increased trend in RASSF2 protein expression. RASSF2 expression was significantly increased with miR-141 and miR-429 antagomir transfection ("P $<0.05$ vs. scramble). Histograms are representative of $n=5$ experimental repeats for all transfections. Representative blots demonstrating significant increase in RASSF 2 expression following transfection with miR-429 antagomirs compared to scramble. miR, microRNA.

tissue. This process of differential miR-200 family expression has been noted by other authors and is suggestive of the EMT process (27). The intra-tumoral microRNA expression varies widely in colon adenocarcinoma, which may also influence the results of expression assays $(9,28)$. While laser capture microdissection is an appropriate methodology for the specific 

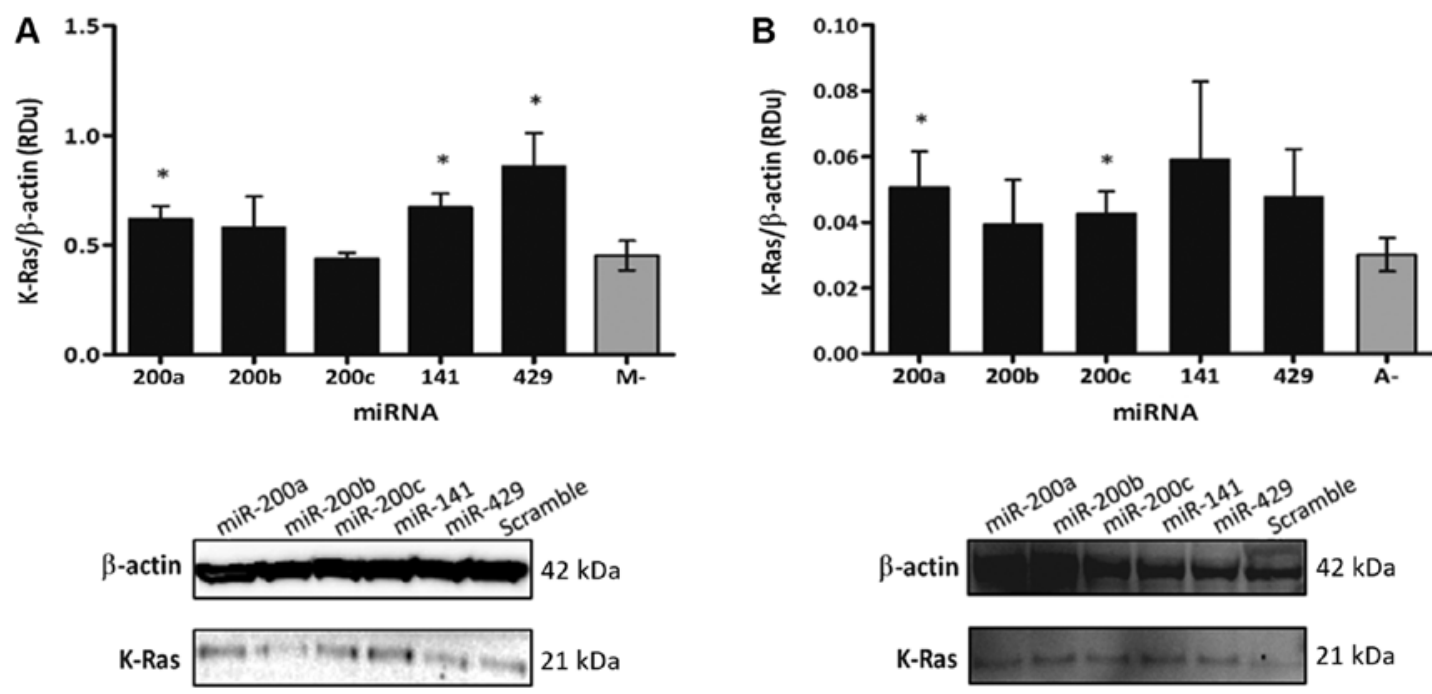

Figure 8. Expression of KRAS protein following transfection of miR-200 mimics or antagomirs. (A) Increased KRAS protein expression in the CCD-841 cell line following transfection of miR-200a, miR-141, and miR-429 mimics compared to scramble (M-). (B) Increased expression of KRAS in the HT-29 following transfection of miR-200a and miR-200c antagomirs compared with scramble (A-). ${ }^{*} \mathrm{P}<0.05$ vs. scramble. miR, microRNA.
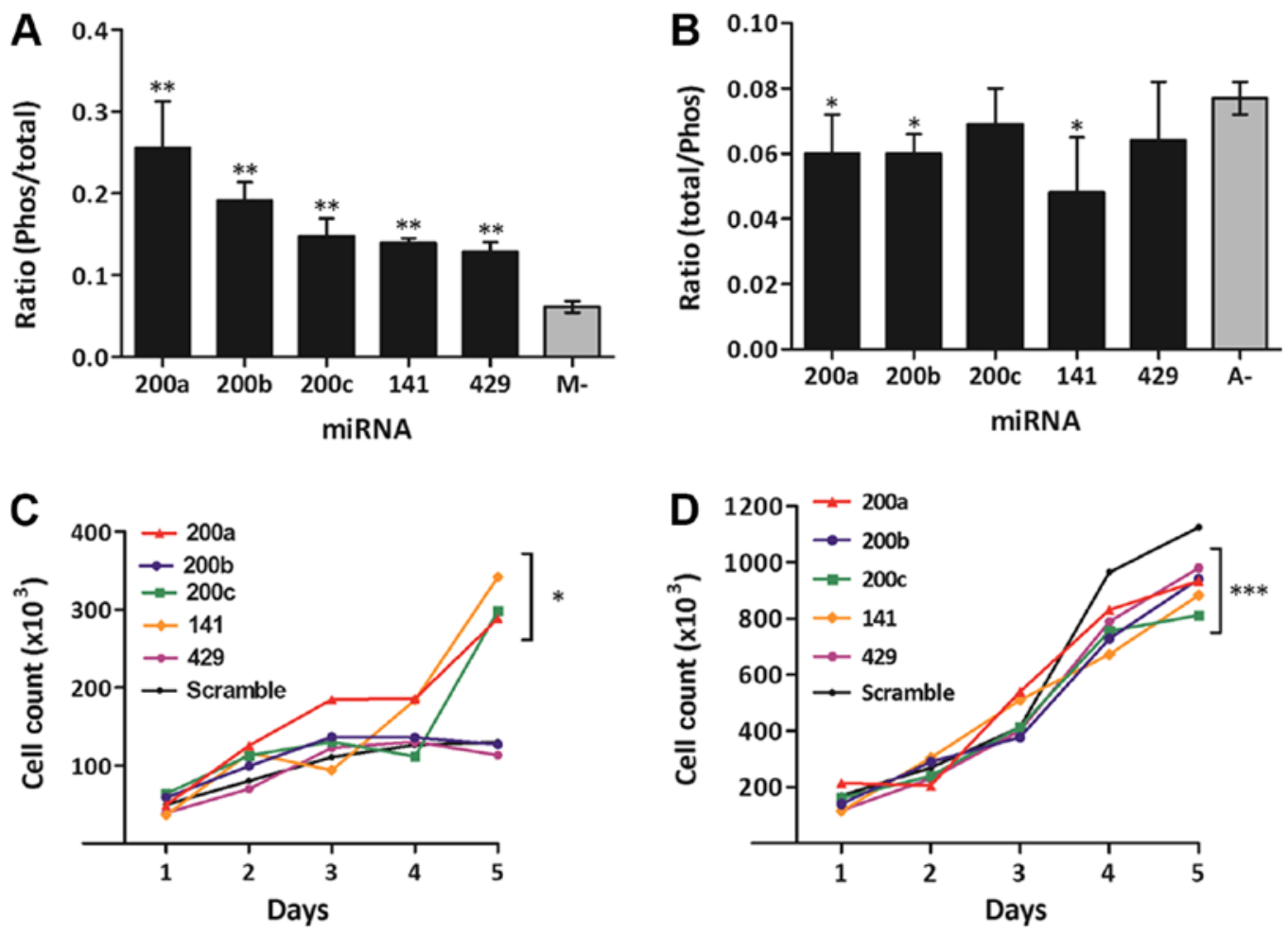

Figure 9. MAPK/ERK pathway activity and cell proliferation. (A) Significant upregulation of the ratio of phosphorylated to total ERK1/2 compared to negative control (M-) indicating increased MAPK pathway activation following transfection with all miR-200 family mimics in the CCD-841 CoN (normal colon epithelial) cell line. ${ }^{* *} \mathrm{P}<0.002$ vs. scramble. (B) Significant decrease in the ratio of ERK1/2 compared to negative control (A-) indicating decreased MAPK pathway activation following transfection with miR-200a, miR-200b, and miR-141 antagomirs in HT-29 (stage III colon cancer) cell line. "P<0.05 vs. scramble. (C) There is significantly increased proliferation in the CCD-841 CoN cell line following transfection with miR-200a, miR-200c, and miR-141 mimics. ${ }^{*} \mathrm{P}<0.05$ vs. scramble. (D) There is significantly decreased cellular proliferation following transfection with antagomirs of all members of the miR-200 family. ${ }^{* * *} \mathrm{P}<0.001$ vs. scramble. miR, microRNA.

identification of tumoral microRNA expression, it is challenging to have appropriate tissue for both RNA and protein analysis.

The miR-200 family could regulate the MAPK/ERK signaling pathway in the current study, which is a known major regulator of cell proliferation (29). There is a large body of evidence that suggests that this pathway is involved in the pathogenesis, progression, and oncogenic CRC behavior $(16,30)$. KRAS was indirectly regulated by the miR-200 family in this study and was a key upstream signaling molecule in this pathway (31). However, oncogenic mutations in KRAS are found in approximately $40 \%$ of colorectal cancers, and there 

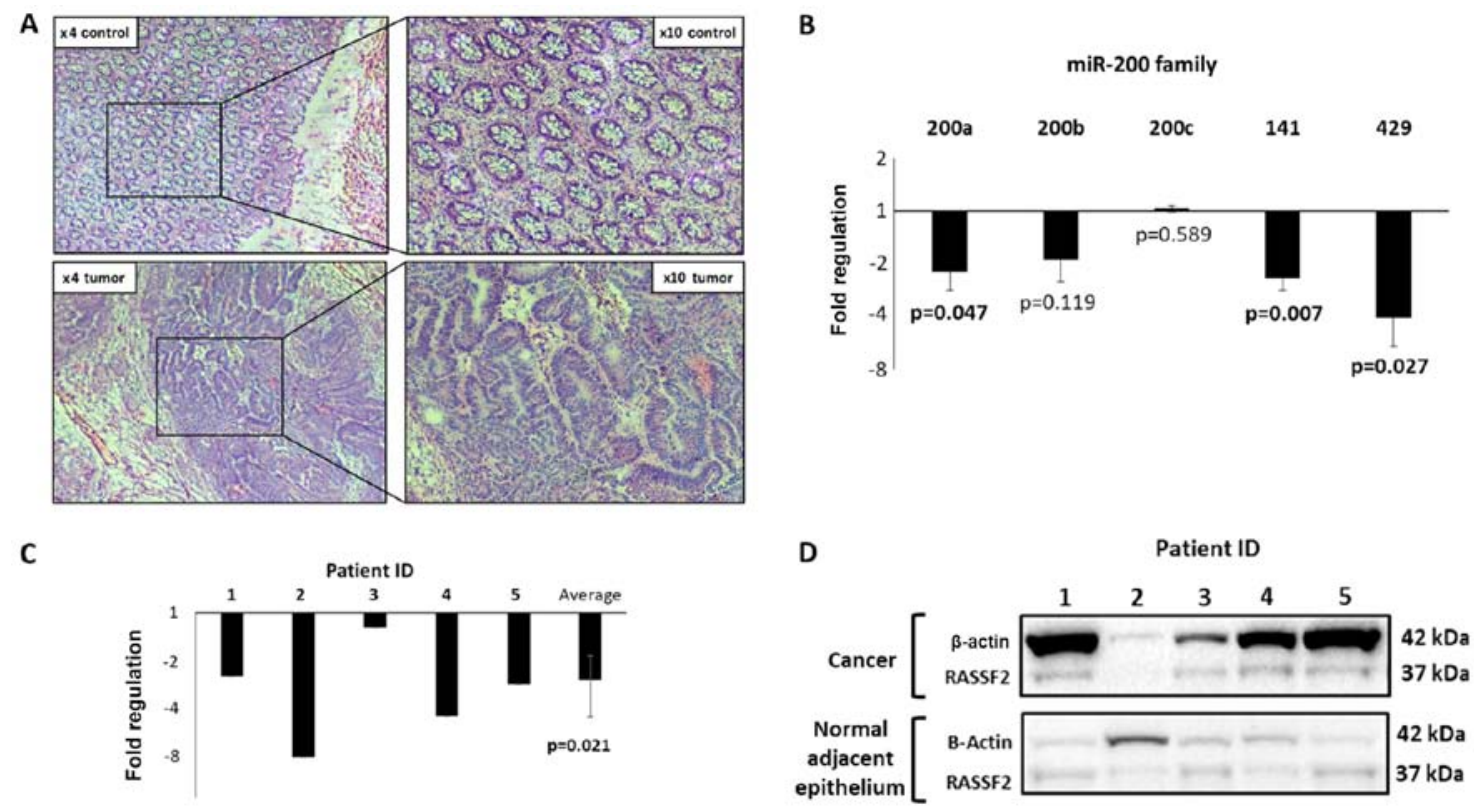

Figure 10. Differences in miR-200 and RASSF2 expression in human colon cancer tissue compared with normal adjacent epithelial tissue from the same patients $(n=5)$. (A) Sample H\&E slides for tumor and control tissue used for reference during laser capture microdissection. (B) We observed downregulation in miR-200a, miR-200b, miR-141, and miR-429, and no change in miR-200c in colon cancer as compared with normal adjacent epithelial tissue using RT-qPCR and U6 for reference. (C) We observed downregulation of RASSF2 mRNA in colon cancer as compared with normal adjacent epithelial tissue; with an average fold change of -2.72 using RT-qPCR and 18S rRNA for reference. (D) A representative western blot showing RASSF2 protein downregulation using $\beta$-actin for reference. We observed a RASSF2: $\beta$-actin of 0.8 for CRC and 5.3 for normal adjacent for a -6.02 fold downregulation. miR, microRNA.

are a number of upstream regulator molecules apart from the miR-200 family (32). Despite this, the interaction between the miR-200 family and KRAS signaling has been observed in different cancers. In an enrichment pathway analysis, the MAPK and EGFR signaling pathways contained the greatest number of targets for miR-200c in a murine breast cancer model (33). Furthermore, miR-200c suppressed proliferation in both wild-type and mutated KRAS breast cancer cell lines (25). Interestingly, in a mutant KRAS lung adenocarcinoma model, overexpression of miR-200a, miR-200b, and miR-429 inhibited tumor growth and metastasis through alternative pathway signaling (34). High Ras activity is accompanied by increased ERK1/2 activity (35).

A significant number of studies examining the miR-200 family in CRC focus on EMT. It has been hypothesized that loss of miR-200 family expression in tumors may facilitate EMT, thereby enhancing tumor migration and invasion $(26,36)$. This has been translated into a number of clinical studies in which low tissue expression of the miR-200 family members is associated with worse overall survival $(37,38)$, cancer-specific survival $(38,39)$, and non-response to chemotherapy (38). The converse proliferative role of the miR-200 family in CRC has been demonstrated in other studies, whereby increased miR-200 expression is associated with proliferation and decreased expression is associated with invasion and migration (27).

The function of the miR-200 family can vary between types of cancer. Increased expression of miR-200a and miR-200c induce a mesenchymal and more aggressive phenotype in melanoma, despite the expected suppression of ZEB1 (40). An alternative signaling pathway though myristoylated alanine-rich protein kinase C substrate (MARCKS) was suggested, which produced a similar phenotype to that of the miR-200 family. Interestingly, Dykxhoorn et al (41) reported increased expression of the miR-200 family in a murine breast cancer cell line, which metastasized to the liver and lung, echoing the suggestion that the miR-200 family may have alternative roles in different cancer types.

This exploratory study summarizes the novel role of the miR-200 family in regulating the MAPK/ERK signaling pathway and subsequent cellular proliferation. Although the miR-200 family have shared seed sequences, they may have individual functions that account for the differences observed in these data. Further study is needed to explore the regulatory functions of the miR-200 family in the MAPK/ERK signaling pathway.

In conclusion, the miR-200 family is significantly increased in colon cancer and directly binds RASSF 2 in the MAPK/ERK signaling pathway. Reduced expression of miR-200 family members leads to decreased MAPK/ERK pathway activity and a reduction in cell proliferation in HT-29 cells. These findings suggest that the miR-200 family may have an oncogenic role in colon cancer and may therefore provide opportunities for targeted therapies.

\section{Acknowledgements}

The authors would like to thank Professor Shesh Rai and Dr Jianmin Pan (Department of Biostatistics and Bioinformatics, University of Louisville, Louisville, KY, USA).

\section{Funding}

The present study was supported in part by the John W. and Barbara Thruston Atwood Price Trust, the Mary K. Oxley Foundation, and the NIH Cancer Education Program at the University of Louisville (grant no. 2R25CA134283-06A1). 


\section{Availability of data and materials}

The datasets used and/or analyzed during the present study are available from the corresponding author on reasonable request.

\section{Authors' contributions}

SG, JVC, SOB and EH conceived and designed the study. JVC, SOB, JFB, BGO, VS, JH, CB, NJG, MRE and HS acquired the data. JVC, SOB and MRE performed the statistical analyses. JVC, SOB, JFG, BGO, VS, JH, CB, NJG, MRE, HS, EH and SG drafted and critically revised the manuscript, and approved the final version of the manuscript.

\section{Ethics approval and consent to participate}

The present study was approved by the Institutional Review Board of the University of Louisville. All patients gave written informed consent for the use of tissues in this study.

\section{Patient consent for publication}

All patients gave their consent for the publication of the data generated from their tissues.

\section{Competing interests}

The authors declare that they have no competing interests.

\section{References}

1. Macfarlane LA and Murphy PR: MicroRNA: Biogenesis, Function, and role in cancer. Curr Genomics 11: 537-561, 2010.

2. Billeter AT, Druen D, Kanaan ZM and Polk HC Jr: MicroRNAs: New helpers for surgeons? Surgery 151: 1-5, 2012.

3. Croce CM: Oncogenes and cancer. N Engl J Med 358: 502-511, 2008.

4. Meltzer PS: Cancer genomics: Small RNAs with big impacts. Nature 435: 745-746, 2005.

5. Zhang B, Pan X, Cobb GP and Anderson TA: microRNAs as oncogenes and tumor suppressors. Dev Biol 302: 1-12, 2007.

6. Shenouda SK and Alahari SK: MicroRNA function in cancer: Oncogene or a tumor suppressor? Cancer Metastasis Rev 28: 369-378, 2009.

7. Humphries B and Yang C: The microRNA-200 family: Small molecules with novel roles in cancer development, progression and therapy. Oncotarget 6: 6472-6498, 2015.

8. Gregory PA, Bert AG, Paterson EL, Barry SC, Tsykin A, Farshid G, Vadas MA, Khew-Goodall Y and Goodall GJ: The miR-200 family and miR-205 regulate epithelial to mesenchymal transition by targeting ZEB1 and SIP1. Nat Cell Biol 10: 593-601, 2008.

9. Paterson EL, Kazenwadel J, Bert AG, Khew-Goodall Y, Ruszkiewicz A and Goodall GJ: Down-regulation of the miRNA-200 family at the invasive front of colorectal cancers with degraded basement membrane indicates EMT is involved in cancer progression. Neoplasia 15: 180-191, 2013.

10. Kumar S, Nag A and Mandal CC: A comprehensive review on miR-200c, A promising cancer biomarker with therapeutic potential. Curr Drug Targets 16: 1381-1403, 2015.

11. Armaghany T, Wilson JD, Chu Q and Mills G: Genetic alterations in colorectal cancer. Gastrointest Cancer Res 5: 19-27, 2012.

12. Vogelstein B and Kinzler KW: Cancer genes and the pathways they control. Nat Med 10: 789-799, 2004.

13. Jancik S, Drabek J, Radzioch D and Hajduch M: Clinical relevance of KRAS in human cancers. J Biomed Biotechnol 2010: 150960,2010

14. Brand TM and Wheeler DL: KRAS mutant colorectal tumors: Past and present. Small GTPases 3: 34-39, 2012.
15. Dhillon AS, Hagan S, Rath O and Kolch W: MAP kinase signalling pathways in cancer. Oncogene 26: 3279-3290, 2007.

16. Wang X, Wang Q, Hu W and Evers BM: Regulation of phorbol ester-mediated TRAF1 induction in human colon cancer cells through a PKC/RAF/ERK/NF-kappaB-dependent pathway. Oncogene 23: 1885-1895, 2004.

17. Vos MD, Ellis CA, Elam C, Ulku AS, Taylor BJ and Clark GJ: RASSF2 is a novel K-Ras-specific effector and potential tumor suppressor. J Biol Chem 278: 28045-28051, 2003.

18. Akino K, Toyota M, Suzuki H, Mita H, Sasaki Y, Ohe-Toyota M, Issa JP, Hinoda Y, Imai K and Tokino T: The Ras effector RASSF2 is a novel tumor-suppressor gene in human colorectal cancer. Gastroenterology 129: 156-169, 2005.

19. Carter JV, Roberts HL, Pan J, Rice JD, Burton JF, Galbraith NJ, Eichenberger MR, Jorden J, Deveaux P, Farmer R, et al: A highly predictive model for diagnosis of colorectal neoplasma using plasma MicroRNA: Improving Specificity and Sensitivity. Ann Surg 264: 575-584, 2016.

20. Livak KJ and Schmittgen TD: Analysis of relative gene expression data using real-time quantitative PCR and the 2(-Delta Delta C(T)) method. Methods 25: 402-408, 2001.

21. Chou CH, Shrestha S, Yang CD, Chang NW, Lin YL, Liao KW, Huang WC, Sun TH, Tu SJ, Lee WH, et al: miRTarBase update 2018: A resource for experimentally validated microRNA-target interactions. Nucleic Acids Res 46: D296-D302, 2018.

22. Hyun S, Lee JH, Jin H, Nam J, Namkoong B, Lee G, Chung J and Kim VN: Conserved MicroRNA miR-8/miR-200 and its target USH/FOG2 control growth by regulating PI3K. Cell 139: 1096-1108, 2009

23. Berg KCG, Eide PW, Eilertsen IA, Johannessen B, Bruun J, Danielsen SA, Bjørnslett M, Meza-Zepeda LA, Eknæs M, Lind GE, et al: Multi-omics of 34 colorectal cancer cell lines-a resource for biomedical studies. Mol Cancer 16: 116, 2017.

24. Zhong X, Zheng L, Shen J, Zhang D, Xiong M, Zhang Y, He X, Tanyi JL, Yang F, Montone KT, et al: Suppression of MicroRNA 200 family expression by oncogenic KRAS activation promotes cell survival and epithelial-mesenchymal transition in KRAS-driven cancer. Mol Cell Biol 36: 2742-2754, 2016.

25. Kopp F, Wagner E and Roidl A: The proto-oncogene KRAS is targeted by miR-200c. Oncotarget 5: 185-195, 2014.

26. O'Brien SJ, Carter JV, Burton JF, Oxford BG, Schmidt MN Hallion JC and Galandiuk S: The role of the miR-200 family in epithelial-mesenchymal transition in colorectal cancer: A systematic review. Int J Cancer 142: 2501-2511, 2018.

27. Hur K, Toiyama Y, Takahashi M, Balaguer F, Nagasaka T, Koike J, Hemmi H, Koi M, Boland CR and Goel A: MicroRNA-200c modulates epithelial-to-mesenchymal transition (EMT) in human colorectal cancer metastasis. Gut 62: 1315-1326, 2013.

28. Bojmar L, Karlsson E, Ellegard S, Olsson H, Björnsson B, Hallböök O, Larsson M, Stål O and Sandström P: The role of microRNA-200 in progression of human colorectal and breast cancer. PLoS One 8: e84815, 2013.

29. Troppmair J, Bruder JT, Munoz H, Lloyd PA, Kyriakis J, Banerjee P, Avruch J and Rapp UR: Mitogen-activated protein kinase/extracellular signal-regulated protein kinase activation by oncogenes, serum and 12-O-tetradecanoylphorbol-13-acetate requires Raf and is necessary for transformation. $J$ Biol Chem 269: 7030-7035, 1994.

30. Fang JY and Richardson BC: The MAPK signalling pathways and colorectal cancer. Lancet Oncol 6: 322-327, 2005.

31. Schubbert S, Bollag G, Lyubynska N, Nguyen H, Kratz CP, Zenker M, Niemeyer CM, Molven A and Shannon K: Biochemical and functional characterization of germ line KRAS mutations. Mol Cell Biol 27: 7765-7770, 2007.

32. Tan $\mathrm{C}$ and $\mathrm{Du} \mathrm{X}$ : KRAS mutation testing in metastatic colorectal cancer. World J Gastroenterol 18: 5171-5180, 2012.

33. Perdigao-Henriques R, Petrocca F, Altschuler G, Thomas MP, Le MT, Tan SM, Hide W and Lieberman J: miR-200 promotes the mesenchymal to epithelial transition by suppressing multiple members of the Zeb2 and Snaill transcriptional repressor complexes. Oncogene 35: 158-172, 2016.

34. Roybal JD, Zang Y, Ahn YH, Yang Y, Gibbons DL, Baird BN, Alvarez C, Thilaganathan N, Liu DD, Saintigny P, et al: miR-200 Inhibits lung adenocarcinoma cell invasion and metastasis by targeting Flt1/VEGFR1. Mol Cancer Res 9: 25-35, 2011.

35. Johnston SR: Farnesyl transferase inhibitors: A novel targeted therapy for cancer. Lancet Oncol 2: 18-26, 2001. 
36. Korpal M, Lee ES, Hu G and Kang Y: The miR-200 family inhibits epithelial-mesenchymal transition and cancer cell migration by direct targeting of E-cadherin transcriptional repressors ZEB1 and ZEB2. J Biol Chem 283: 14910-14914, 2008.

37. Diaz T, Tejero R, Moreno I, Ferrer G, Cordeiro A, Artells R, Navarro A,Hernandez R, Tapia G and Monzo M: Role of miR-200 family members in survival of colorectal cancer patients treated with fluoropyrimidines. J Surg Oncol 109: 676-683, 2014.

38. Bhangu A, Wood G, Brown G, Darzi A, Tekkis P and Goldin R The role of epithelial mesenchymal transition and resistance to neoadjuvant therapy in locally advanced rectal cancer. Colorectal Dis 16: O133-O143, 2014.

39. Pichler M, Ress AL, Winter E, Stiegelbauer V, Karbiener M, Schwarzenbacher D, Scheideler M, Ivan C, Jahn SW, Kiesslich T, et al: MiR-200a regulates epithelial to mesenchymal transition-related gene expression and determines prognosis in colorectal cancer patients. Br J Cancer 110: 1614-1621, 2014.
40. Elson-Schwab I, Lorentzen A and Marshall CJ: MicroRNA-200 family members differentially regulate morphological plasticity and mode of melanoma cell invasion. PLoS One 5: pii: e13176, 2010.

41. Dykxhoorn DM, Wu Y, Xie H, Yu F, Lal A, Petrocca F, Martinvalet D, Song E, Lim B and Lieberman J: miR-200 enhances mouse breast cancer cell colonization to form distant metastases. PLoS One 4: e7181, 2009.

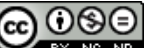

$$
\begin{aligned}
& \text { This work is licensed under a Creative Commons } \\
& \text { Attribution-NonCommercial-NoDerivatives } 4.0 \\
& \text { International (CC BY-NC-ND 4.0) License. }
\end{aligned}
$$

